\title{
RUBRAXHANTONE DARI Garcinia forbesii KING. DAN BIOAKTIVITASNYA
}

\author{
Yohannes Alen', Novi Safitri ${ }^{1}$, Dachriyanus ${ }^{1}$, A. Manaf Ali ${ }^{2}$, N. H. Ladjis ${ }^{2}$ \\ dan M. V. Sargent ${ }^{3}$, \\ ${ }^{1}$ Jurusan Farmasi FMIPA, Universitas Andalas Padang. \\ ${ }^{2}$ Bio-sciences Laboratory, University Putra Malaysia, K.L. Malaysia \\ ${ }^{3}$ Department of Chemistry, University of Western Australia, Australia.
}

\begin{abstract}
The rubraxhantone compound was isolated firstly from antimicrobial fraction of the bark of Garcinia forbesii King. (Famili Guttiferae) by chromatographic method. The structure of this compound was elucidated based on its spectral data properties. The isolated compound had a significant antimicrobial properties against the selected microbes by diffusion method.
\end{abstract}

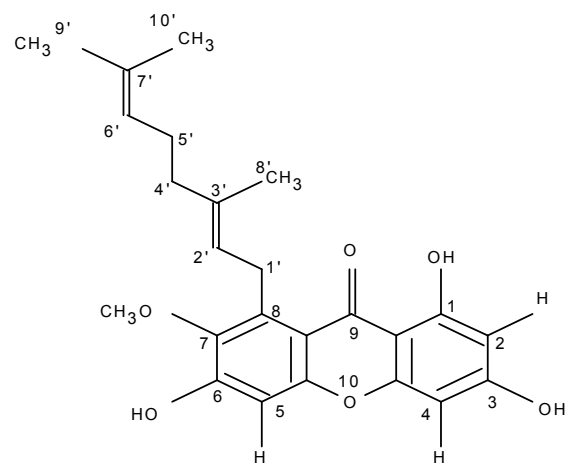

Keywords : antimicrobial, Garcinia forbesii King., chromatographic, diffusion method.

\section{PENDAHULUAN}

Garcinia forbesii King. (Famili Guttiferae) secara tradisional telah digunakan oleh masyarakat Harau Payakumbuh sebagai rempah-rempah. Genus ini digunakan juga sebagai pengobatan dan kosmetik. Dari hasil penelitian yang telah dilakukan, banyak spesies dari genus Garcinia ini mengandung senyawa antimikroba, antikanker, antioksidan dan pelangsing ${ }^{[1]}$.

Berdasarkan penelusuran pustaka beberapa hasil penelitian yang telah dilakukan terhadap species ini ada yang mengandung senyawa golongan xanthon ${ }^{[2,3]}$. Dari genus garcinia telah banyak diketahui kandungannya, antara lain ómangostin, garciniafuran, dimetilmangostin, mangostanin, gertanin yang diisolasi dari Garcinia mangostana ${ }^{[4,5]}$. Dari tumbuhan $G$. cowa Khran. Ditemukan senyawa cowanin, cowanol, cowaxanthon ${ }^{[5]}$. Dari G. tetranda ditemukan senyawa thwaitesixanthon ${ }^{[6]}$. Dalam $G$. polyantha terkandung senyawa isoheediaxanthon ${ }^{[7]}$.

Penggunaan farmakologis dari genus garcinia ini telah banyak diketahui terutama dari senyawa xanthon yang terkandung di dalamnya. Senyawa mangostin yang terkandung dalam $G$. mangostana berguna sebagai antiinflamasi pada dosis $50 \mathrm{mg} / \mathrm{kg} \mathrm{BB}$ dan sebagai antimikroba ${ }^{[7]}$. Tumbuhan $G$. nervosa digunakan oleh masyarakat sebagai obat diare, antiinflamsi, antimikroba dan mengobati infeksi pada kulit ${ }^{[8]}$.). Daun dari $G$. cowa dan G. microstigma digunakan untuk mengobati penderita parkinson ${ }^{[1]}$. Tumbuhan Garcinia forbesii King mengandung xanthon sebagai hasil metabolit sekunder. Pada kulit batang tumbuhan ini terkandung senyawa forbesione ${ }^{[2]}$ piranojacareubin dan 
forbexanthon ${ }^{[3]}, 1,3,7$, trihidroksi-2-(metilbut2-enil) xanthon.

\section{METODOLOGI}

\section{Umum}

Alat-alat yang digunakan untuk pengerjaan isolasi: seperangkat peralatan destilasi, seperangkat peralatan rotary evaporator, gelas ukur dengan berbagai ukuran, plat tetes, corong, kapas, kertas saring (Whatman ${ }^{\circledR}$ ), aluminium foil, penangas air, lampu uv $\lambda 254$ $\mathrm{nm}$ (Betrachter Lamag), kolom kromatografi dengan berbagai ukuran, perangkat kromatografi radial (Kromatotron ${ }^{\circledR}$ model 7924 Harison Research USA), bejana kromatografi (chamber), spatel, kapiler, botol, vial, spektroskopi IR (Digilab FTS-45), spektroskopi ${ }^{13} \mathrm{C}$ RMI (Bruker ADV $125 \mathrm{MHz}$ ), spektroskopi ${ }^{1} \mathrm{H}$ RMI (Bruker ADV $500 \mathrm{MHz}$ ), COSY (Corelation Spectroscopi), spektroskopi massa (Fison VG Autospec) $(70 \mathrm{eV})$ dan "Fisher-Jhon Melting Point Aparatus".

\section{Alat}

Erlenmeyer dengan berbagai ukuran, pinset, pipet mikro (Biohit Proline ${ }^{\circledR}$ ), timbangan analitik (Metler $\mathrm{PM}^{\circledR} 200$ ), cawan petri, jarum ose, kertas cakram (Whatman ${ }^{\circledR}$ No. 3), kertas perkamen, kapas, kain kassa, benang, lampu spiritus, hotplate (IEC ${ }^{\circledR}$ ), autoklaf (All American ${ }^{\circledR}$ Model No. 25X), inkubator
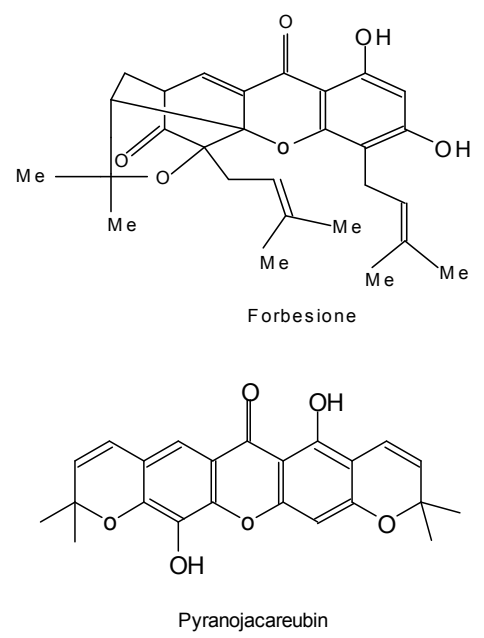

Penyarian sampel dilakukan dengan cara maserasi karena maserasi merupakan prosedur
(Gallenkamp Plus ${ }^{\circledR}$ ), lemari aseptis, tabung reaksi, stirer magnetik, vorteks (Fisons WhirliMixer ${ }^{\mathrm{TM}}$ ), jangka sorong, plat titer mikro dan sheaker.

\section{Bahan}

Kulit batang (kering) tumbuhan Garcinia griffithii T. Anders, diambil pada tanggal 28 April 2002, di daerah Sarasah Bonta Harau Kabupaten Lima Puluh Kota, Sumatera Barat. Air suling, metanol, $n$-heksan, etil asetat, butanol, natrium sulfat anhidrat, silika gel 60 $(40-63 \mu \mathrm{m})\left(\right.$ Merck $\left.^{\circledR}\right)$, plat silika 60 GF 254 $\left(\right.$ Merck $\left.^{\circledR}\right)$. Larutan $\mathrm{NaCl}$ fisiologis, Nutrien Agar (NA) $\left(\right.$ Merck $\left.^{\circledR}\right)$, Sabouraud Dekstrosa Agar (SDA) (Merck ${ }^{\circledR}$ ) dan mikroba uji yang terdiri dari : Staphylococcus aureus ATCC 25923, Staphylococcus epidermidis ATCC 12228, Micrococcus luteus ATCC 9341, Pseudomonas aeruginosa ATCC 10701, Eschericia coli ATCC 25923, Candida albicans ATCC 10231 dan Trichophyton mentagrophytes ATCC 5431.

\section{Prosedur}

Isolasi senyawa aktif antimikroba dari kulit batang Garcinia forbesii King. dilakukan dengan perajangan kulit batangnya. Perajangan ini dimaksudkan untuk memperluas permukaan sampel agar kontak antara pelarut dengan sampel semakin luas sehingga mempermudah penetrasi pelarut kedalam membran sel dan proses pelarutan senyawa-senyawa yang terkandung di dalam sampel.<smiles>CC(C)=CCc1c(O)cc2oc3ccc(O)cc3c(=O)c2c1O</smiles>

1,3,7-trihidroksi-2-(metilbut-2-enil)xanthon<smiles>COc1cc(O)c2c(c1)OC1C(O)=C3OC(C)(C)C=CC3=CC1C2O</smiles>

sederhana untuk mendapatkan ekstrak karena hanya dengan merendam sampel dalam pelarut 
selama beberapa hari dan sesekali dikocok. Metanol digunakan sebagai pelarut dalam maserasi ini karena metanol merupakan pelarut yang dapat melarutkan hampir semua senyawa organik dalam tumbuhan, baik polar maupun non polar dan metanol mepunyai titik didih yang rendah $\left(65^{\circ} \mathrm{C}\right)$ sehingga mudah diuapkan. Ekstrak metanol yang diperoleh diuapkan pelarutnya secara in vacuo, karena dalam keadaan vakum tekanan uap pelarut akan menjadi turun dan pelarut akan mendidih pada temperatur lebih rendah dari titik didihnya sehingga dapat mengurangi kerusakan senyawa termolabil yang ada didalam sampel.

Fraksinasi dilakukan dengan menggunakan pelarut berdasarkan tingkat kepolarannya. Pelarut $n$-heksan akan menarik senyawasenyawa non polar, etil asetat untuk menarik senyawa semi polar dan senyawa polar ditarik dengan pelarut butanol. Fraksi yang didapat dipekatkan in vacuo sehingga didapat ekstrak kental untuk setiap fraksi.

Ekstrak kental metanol dan ketiga fraksi dilakukan uji aktivitas antimikroba dengan metoda difusi agar. Mikroba uji yang digunakan yaitu mikroba yang bersifat patogen dan merugikan terhadap manusia yang umumnya ditemukan pada kulit dan saluran pencernaan yang terdiri dari bakteri gram positif (Staphylococcus aureus, Staphylococcus epidermidis, Micrococcus luteus), bakteri gram negatif (Pseudomonas aeruginosa, Eschericia coli), jamur Candida albicans dan Tricophyton mentagrophytes. Untuk mengukur transmitannya mikroba uji disuspensikan kedalam larutan $\mathrm{NaCl}$ fisiologis yang bertujuan memberikan lingkungan yang isotonik bagi mikroba, sebab jika keadaan hipertonik maka cairan sel akan keluar dan jika hipotonik sel akan mengembang dan pecah. Metoda difusi agar dipilih karena metoda ini relatif sederhana dan hasil yang didapat cukup teliti untuk mengetahui adanya aktivitas antimikroba. Daerah bening disekeliling cakram menandakan tidak adanya mikroba yang tumbuh, hal ini menunjukkan bahwa sampel mempunyai aktivitas menghambat pertumbuhan mikroba. Hasil pengujian aktivitas antimikroba dari sampel uji dengan konsentrasi $10 \% \mathrm{~b} / \mathrm{v}$ untuk ekstrak metanol dan $1 \% \mathrm{~b} / \mathrm{v}$ untuk fraksi menunjukkan bahwa ekstrak metanol dan semua fraksi aktif terhadap semua bakteri yang digunakan namun tidak aktif terhadap jamur, dan fraksi etil asetat memberikan diameter hambatan yang lebih besar terhadap mikroba uji dibandingkan fraksi heksan dan butanol.

Fraksi etil asetat selanjutnya dikromatografi kolom menggunakan fasa diam silika gel 60 $(40-63 \mu \mathrm{m})$ dan fasa gerak $n$-heksan, etil asetat dan metanol dengan sistem SGP atau "Step Gradient Polarity" yaitu dengan menggunakan pelarut yang kepolarannya ditingkatkan secara perlahan-lahan sehingga didapatkan pemisahan yang baik. Disini juga dilakukan kromatografi radial untuk mendapatkan senyawa murni. Pemisahan senyawa dengan kromatografi radial ini lebih bagus, sehingga baik sekali digunakan untuk pemisahan campuran senyawa-senyawa dimana pola kromatogramnya pada plat KLT menunjukkan noda yang berdekatan yang sukar dipisahkan secara kromatografi kolom biasa. Pada prinsipnya kromatografi radial merupakan kromatografi lapis tipis preparatif dengan aliran fasa gerak yang dipercepat oleh gaya sentrifugal.

Fraksi yang telah menunjukkan satu noda pada plat KLT direkristalisasi dengan menggunakan campuran pelarut $n$-heksan, etil asetat sehingga diperoleh senyawa murni yang telah menunjukkan satu noda pada plat KLT. Dari fraksi etil asetat ini dihasilkan 3 senyawa murni yaitu senyawa A berupa kristal kuning yang dimurnikan dengan rekristalisasi dengan $n$-heksan dan etil asetat, senyawa B dan C berupa minyak.

Penentuan aktivitas antimikroba senyawa A, B, $\mathrm{C}$ dilakukan dengan metoda difusi agar dengan kadar tiap cakram $100 ; 50,0 ; 30,0 ; 15,0$; dan $10,0 \mu \mathrm{g}$. Untuk mengetahui aktivitas antimikroba senyawa ini digunakan antibiotik pembanding yaitu tetrasiklin yang merupakan antibiotik spektrum luas yang dapat menghambat pertumbuhan bakteri gram positif dan gram negatif. Konsentrasi tetrasiklin yang dipakai $30 \mu \mathrm{g} /$ cakram dan untuk jamur digunakan klortrimazol sebagai kontrol positif dengan kadar $10 \mu \mathrm{g} / \mathrm{cakram}$.

Dari uji aktivitas antimikroba yang telah dilakukan ternyata senyawa A mempunyai 
aktivitas yang lebih tinggi menghambat pertumbuhan bakteri Staphylococcus aureus, Staphylococcus epidermidis, Micrococcus luteus, Pseudomonas aeruginosa, Eschericia coli, dan tidak aktif terhadap jamur Trichopython mentagrophytes dan Candida albicans. Di sini dapat diketahui bahwa pada konsentrasi yang sama antara senyawa A dengan tetrasiklin $(30 \mu \mathrm{g} /$ cakram $)$, aktivitas senyawa A adalah 0,5-0,6 x aktivitas tetrasiklin.

Untuk penentuan KHM digunakan metoda dilusi dengan "96-Well microtiterplate". Pada metoda ini hasil yang diperoleh lebih sensitif karena konsentrasi senyawa yang digunakan dalam ppm (part per million). Dari metoda ini dapat diketahui bahwa senyawa A mempunyai KHM yang lebih rendah dari senyawa B dan C. Larutan induk dibuat 1000 ppm berdasarkan pada konsentrasi terakhir pada metoda difusi agar.

Selanjutnya dilakukan karakterisasi terhadap senyawa A ini. Dari pemeriksaan jarak leleh senyawa A menggunakan alat "Fisher -Jhon Melting Point Apparatus“, diketahui bahwa senyawa A ini memiliki jarak leleh 205 $206^{\circ} \mathrm{C}$. Nilai ini menunjukkan bahwa senyawa A telah murni karena jarak lelehnya yang sempit. Dari pemeriksaan senyawa A dengan reaksi kimia, ternyata senyawa A ini memberikan warna hijau dengan larutan besi(III) klorida $1 \%$, ini menunjukkan bahwa ia merupakan golongan fenolik. Dengan reagen sianidin test, senyawa A memberikan reaksi negatif dan Ini menunjukkan senyawa A bukanlah suatu flavonoid.

Penentuan struktur senyawa aktif anti-mikroba hasil isolasi dilakukan menggunakan spektrometer yang meliputi spektrometer Ultraviolet (UV), Inframerah (IR), Resonansi Magnetik Inti (RMI) dan massa (MS).

\section{HASIL DAN PEMBAHASAN}

Dari spektrum IR dapat diketahui bahwa senyawa ini memberikan serapan pada bilangan gelombang $3450 \mathrm{~cm}^{-1}$ yang berasal dari serapan $\mathrm{OH}$ bebas. Terjadinya "broad spectrum" diduga berasal dari gugus $\mathrm{OH}$ lain yang memiliki ikatan hidrogen. Pada bilangan gelombang sekitar $2950 \mathrm{~cm}^{-1}$ memperlihatkan adanya $\mathrm{C}-\mathrm{H}$ alifatis dan pada $1655 \mathrm{~cm}^{-1}$ memperlihatkan adanya $\mathrm{C}=\mathrm{O}$. Pada bilangan gelombang $1390 \mathrm{~cm}^{-1}$ terlihat serapan yang lemah utuk $\left(\mathrm{CH}_{3}\right)_{2}$ atau gem-dimetil. Pada bilangan gelombang $3238 \mathrm{~cm}^{-1}$ memperliharkan regang $\mathrm{C}-\mathrm{H}$ aromatis, dan pada panjang gelombang $1162 \mathrm{~cm}^{-1}$ merupakan regangan $\mathrm{C}-\mathrm{O}-\mathrm{C}$.

Pemeriksaan spektrum ultraviolet senyawa A dalam metanol memberikan serapan maximum pada panjang gelombang 240,9 dan $311,3 \mathrm{~nm}$ yang memperlihatkan bahwa senyawa ini memiliki inti xanthon.

Dari pemeriksaan spektrum Massa senyawa A dengan metoda HREI (High Resolution Electron Impact) menunjukkan Berat Molekul senyawa ini 410,1728 yang menyatakan bahwa senyawa ini memiliki 24 atom $\mathrm{C}, 26$ atom $\mathrm{H}$ dan 6 atom $\mathrm{O}$ dengan rumus molekul $\mathrm{C}_{24} \mathrm{H}_{26} \mathrm{O}_{6}$.

Dari spektrum ${ }^{1} \mathrm{H}-\mathrm{NMR}$ senyawa A dalam d6aseton terlihat 1 buah sinyal singlet pada 13,47 ppm yang diduga berasal dari atom $\mathrm{H}$ yang membentuk ikatan hidrogen dengan atom $\mathrm{O}$ yang berasal dari gugus $\mathrm{C}=\mathrm{O}$, sehingga berkemungkinan ia berada pada posisi C-1 berdekatan dengan gugus karbonil. Sedangkan pada pergeseran kimia 9,52 ppm terlihat sinyal melebar dengan nilai integritas dua, dan ini menunjukkan adanya dua buah $\mathrm{O}-\mathrm{H}$ bebas.

Adanya 3 buah atom $\mathrm{H}$ yang terikat pada cicin aromatik, yakni sinyal yang muncul pada 6,17 $-6,80 \mathrm{ppm}$. Diantaranya sinyal doublet pada 6,17 ppm dengan konstanta kopling $2,1 \mathrm{~Hz}$ yang mengindikasikan adanya posisi meta pada cincin aromatik. Sinyal pada $6,17 \mathrm{ppm}$ ini merupakan sinyal dari atom $\mathrm{H}$ pada $\mathrm{C}-2$ yang terkopling oleh atom $\mathrm{H}$ pada $\mathrm{C}-4$. Sinyal doublet pada 6,28 ppm dengan konstanta kopling 2,1 Hz merupakan sinyal dari atom $\mathrm{H}$ pada C-4 yang terkopling oleh atom $\mathrm{H}$ pada $\mathrm{C}$ 2 (Gambar 1). Sedangkan pada pergeseran kimia $6,80 \mathrm{ppm}$ terlihat sinyal singlet tanpa konstanta kopling yang merupakan sinyal dari 1 atom $\mathrm{H}$ pada posisi $\mathrm{C}-5$. Pada pergeseran kimia 3,80 ppm terdapat sinyal singlet yang merupakan sinyal dari 3 buah proton $\mathrm{H}$ yang terikat sebagai metoksi aromatik dimana disini terjadi pergeseran kedaerah "downfield" akibat berdekatan dengan atom yang memiliki keelektro-negatifan. Di daerah upfield terdapat 
tiga sinyal singlet pada $\delta 1,50 \mathrm{ppm}, 1,55 \mathrm{ppm}$ dan 1,82 ppm yang merupakan sinyal dari tiga buah metil yang masing-masing terletak pada posisi C-8', C-9' dan C-3'a. Sinyal singlet menunjukkan bahwa metil ini terikat dengan atom C kuartener. Dengan tidak adanya kopling para pada atom $\mathrm{H}$ yang terletak pada posisi C-5, mengin-dikasikan bahwa pada posisi C-8 tidak ada proton dan diduga pada posisi ini terjadi ikatan dengan grup lain ini didukung oleh spektrum COSY dan HMBC.

Dari spektrum ${ }^{13} \mathrm{C}-\mathrm{NMR}$ senyawa A dalam d6aseton, diketahui bahwa senyawa ini memiliki 24 atom carbon. Dengan teknik DEPT diketahui adanya 4 buah atom $C$ primer (metil), 3 buah atom $\mathrm{C}$ sekunder (metilen), 5 buah atom $\mathrm{C}$ tersier (metin) dan 12 buah atom $\mathrm{C}$ kuartener. Gugus metil terlihat pada pergeseran kimia 16,63 ppm, 17,75 ppm, 25,82 ppm, sedangkan pada $61,46 \mathrm{ppm}$ terlihat adanya atom $\mathrm{C}$ primer (metil) yang terikat dengan atom $\mathrm{O}$ (metoksi). Gugus keton yang ada pada inti xanthon terlihat dengan adanya atom $\mathrm{C}$ kuartener pada $182,73 \mathrm{ppm}$, sedangkan gugus hidroksil terlihat dengan adanya atom $\mathrm{C}$ kuartener pada inti xanthon dengan pergeseran kimia 165,38 ppm; 164,92 ppm dan 157,50 ppm. Atom C kuartener lainnya pada inti xanthon adalah 157,96 ppm; 156,30 ppm; 144,59 ppm; 138,27 ppm; 112,02 ppm; 103,81 ppm; dan 138,27 ppm. Pada pergeseran kimia 98,77 ppm; 93,86 ppm; 102,84 ppm merupakan atom $\mathrm{C}$ tersier yang terdapat pada inti xanthon. Sinyal C tersier lainnya yaitu pada 124,87 ppm; 125,21 ppm yang berada pada posisi C-2' dan C-6'. Pada pergeseran 131,58 ppm dan 135,11 ppm merupakan $\mathrm{C}$ kuartener pada molekul geranil pada posisi berturut-turut C-7' dan C-3'. Pada pergeseran kimia 5,04 ppm terlihat sinyal "triplet" yang merupakan sinyal dari proton pada ikatan rangkap yang bertetangga dengan $\mathrm{CH}_{2}$. Dari spektrum COSY terlihat bahwa atom dengan $\delta_{\mathrm{H}}$ 5,04 ppm ini mempunyai "bond coupling" dengan atom pada $\delta_{\mathrm{H}} 2,06 \mathrm{ppm}$ yang merupakan pergeseran kimia untuk $\mathrm{CH}_{2}$ yang muncul sebagai sinyal "multiplet triplet". Sinyal "multiplet triplet" ini mengindikasikan bahwa $\mathrm{CH}_{2}$ ini bertetangga dengan atom yang mempunyai 2 proton. Dari spektrum HMBC terlihat bahwa atom dengan $\delta_{\mathrm{H}} 2,06 \mathrm{ppm}$ ini punya "bond coupling" dengan atom $\mathrm{C}$ pada $\delta_{\mathrm{H}}$ 1,96 ppm yang merupakan sinyal untuk $\mathrm{CH}_{2}$.

Pada pergeseran kimia 5,28 ppm terdapat sinyal "broadtriplet" yang merupakan sinyal untuk proton pada ikatan rangkap yang bertetangga dengan $\mathrm{CH}_{2}$. Dari spektrum COSY terlihat bahwa atom $\mathrm{C}$ dengan $\delta_{\mathrm{H}} 5,28 \mathrm{ppm}$ ini punya "bond coupling" dengan atom $\mathrm{C}$ pada $\delta_{\mathrm{H}}$ 4,10 ppm yang merupakan sinyal untuk $\mathrm{CH}_{2}$. Sinyal pada $\delta_{\mathrm{H}} 4,10 \mathrm{ppm}$ ini muncul sebagai sinyal "broad doublet" yang mengindikasikan bahwa ia bertetangga dengan atom $\mathrm{C}$ kuartener dan karena sinyal ini begeser ke daerah "down field" mengindikasikan bahwa ia berikatan dengan inti benzen.

Dari spektrum C-RMI terlihat 3 gugus metil yaitu pada pergeseran kimia 17,75 ppm, 25,82 ppm dan 16,63 ppm. Dari spektrum HMBC terlihat bahwa gugus metil pada pergeseran kimia $17,75 \mathrm{ppm}\left(\delta_{\mathrm{H}} 1,50 \mathrm{ppm}\right)$ dan $\delta_{\mathrm{C}} 25,82$ $\left(\delta_{\mathrm{H}} 1,55 \mathrm{ppm}\right)$ mempunyai "bond kopling" dengan atom $\mathrm{C}$ pada $\delta_{\mathrm{C}} 125,21 \mathrm{ppm}\left(\delta_{\mathrm{H}} 5,04\right.$ ppm), sedangkan untuk gugus metil pada $\delta_{\mathrm{C}}$ $16,63 \mathrm{ppm}\left(\delta_{\mathrm{H}} 1,82\right)$ berdekatan dengan atom $\mathrm{C}$ pada $\delta_{\mathrm{C}} 124,87 \mathrm{ppm}\left(\delta_{\mathrm{H}} 5,28 \mathrm{ppm}\right)$. Sehingga di sini terbentuk dua sistem. Dengan adanya "bond coupling" antara atom $\mathrm{H}$ pada $\delta_{\mathrm{H}}$ 1,96 dengan atom $\mathrm{C}$ pada $\delta_{\mathrm{C}} 16,63 \mathrm{ppm}\left(\delta_{\mathrm{H}}\right.$ $1,82 \mathrm{ppm}$ ) yang terlihat pada spektrum HMBC, dan dari spektrum COSY terlihat pula hubungan antara atom $\mathrm{H}$ pada $\delta_{\mathrm{H}} 1,96$ dengan atom $\mathrm{H}$ pada $\delta_{\mathrm{H}} 1,82 \mathrm{ppm}$ mengindikasikan bahwa kedua sistem yang terbentuk saling berhubungan pada atom $\mathrm{C}$ dengan $\delta_{\mathrm{H}} 1,96 \mathrm{ppm}$ (Gambar 2) sehingga membentuk molekul geranil.

Karena pada spektoskopi massa dengan metoda HREI menunjukkan bahwa senyawa ini terdiri dari 24 atom $\mathrm{C}$, dimana 10 atom $\mathrm{C}$ nya telah membentuk gugus geranil sedangkan satu buah atom $\mathrm{C}$ membentuk gugus metoksi sehingga 13 atom $\mathrm{C}$ sisa mengindikasikan bahwa pada senyawa ini terdapat inti xanthon seperti yang diperlihatkan oleh spektrum UV. 
Pada pemeriksaan spektrum HMBC menunjukkan bahwa atom $\mathrm{H}$ pada cincin aromatis yang terkopling secara meta terikat pada cincin B dari inti xanthon, sebab terdapatnya "long range" kopling antara atom $\mathrm{C}$ dengan pergeseran kimia 165,38 ppm (C-1) dengan atom $\mathrm{H}$ pada pergeseran kimia 6,28 ppm (C-4). Sedangkan satu atom H lainnya terletak pada cincin A. Atom $\mathrm{C}$ dengan $\delta_{\mathrm{H}}$ 4,10 ppm (dari gugus geranil) tidak mempunyai "bond coupling" dengan atom $\mathrm{C}$ pada $\delta_{\mathrm{C}} 165,38 \mathrm{ppm}$, ini mengindikasikan bahwa gugus geranil tidak berikatan pada cincin B dari inti xanthon. Dari spektrum $\mathrm{HMBC}$ atom $\mathrm{H}$ dengan $\delta_{\mathrm{H}} 6,80 \mathrm{ppm}$ punya "bond coupling" dengan atom $\mathrm{C}$ pada $\delta_{\mathrm{C}}$ $156,30 \mathrm{ppm} ; 157,50 \mathrm{ppm} ; 144,59 \mathrm{ppm}$. Ini mengindikasikan bahwa atom $\mathrm{H}$ ini berada
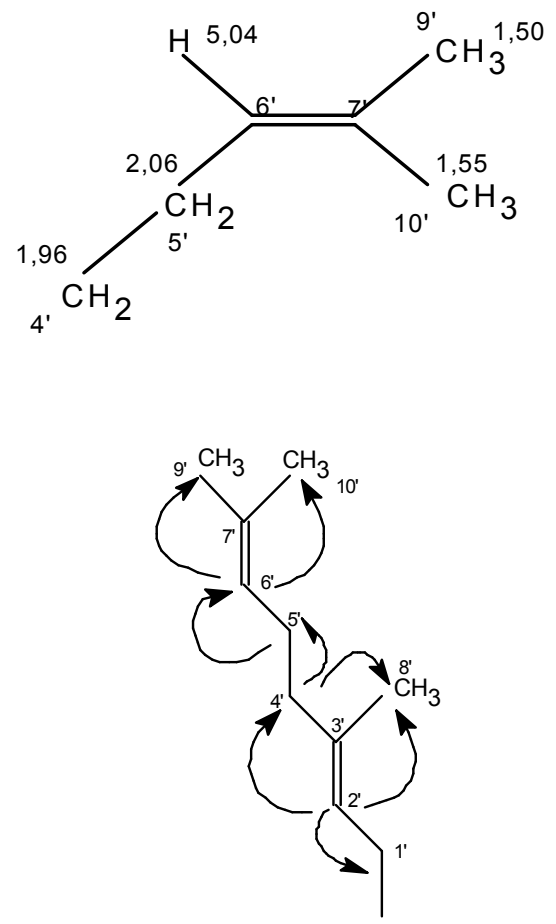

gambar 3

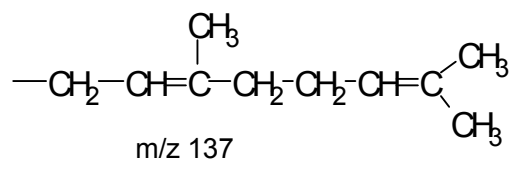

pada cincin A inti xanthon pada posisi C-5, sedangkan yang lainnya berturut-turut pada $\mathrm{C}$ 6, C-10a, dan C-7. Dengan adanya "bond coupling" antara atom $\mathrm{H}$ pada pergeseran kimia 4,10 ppm (C - 1') terhadap atom $\mathrm{C}$ dengan pergeseran kimia 112,02 ppm (C-8a) dan atom $C$ pada pergeseran kimia $144,59 \mathrm{ppm}$ (C-7), mengindikasikan bahwa pada posisi C8 terjadi ikatan antara inti xanthon dengan molekul geranil (Gambar 3).<smiles>COc1c(O)oc2c3cc4ccccc4c(O)c3c(=O)c=2c(C)c1C</smiles>

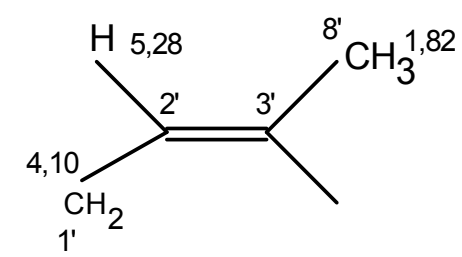

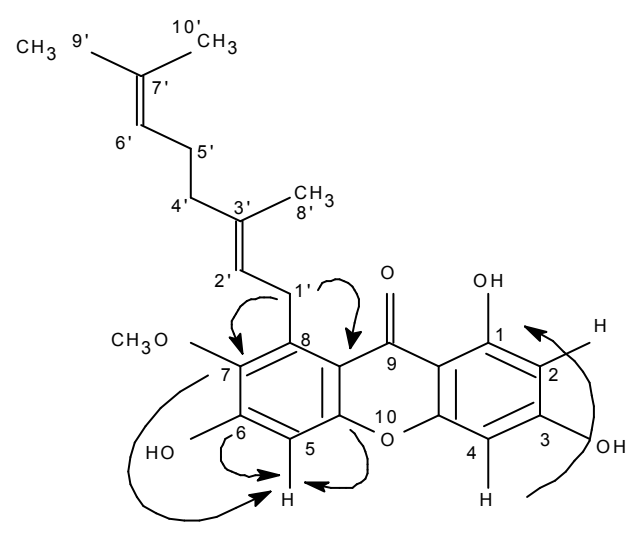

Gambar 4

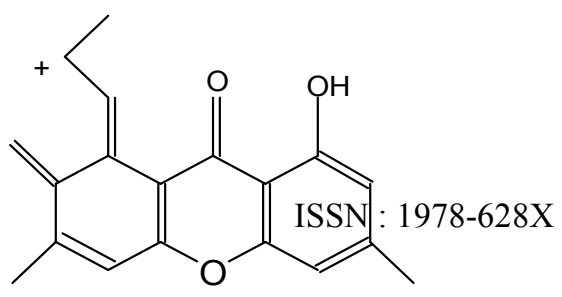


<smiles>COc1cc2c(=O)c3c(O)cc(O)cc3oc2cc1O</smiles>

Dari pemeriksaan spektrum massa terlihat fragmen-fragmen yang lepas dari senyawa A. Fragmen dengan puncak $\mathrm{m} / \mathrm{z} \quad 341$ mengindikasikan lepasnya fragmen dengan $\mathrm{m} / \mathrm{z} 69$ yang merupakan fragmen yang umum lepas pada molekul geranil $\left(\mathrm{C}_{5} \mathrm{H}_{9}\right)$ yaitu lepasnya molekul prenil $\left(\mathrm{C}_{5} \mathrm{H}_{9}\right)$. Puncak dengan m/z 299 merupakan puncak untuk senyawa 8-geranyl-7 metoksi xanthon dan ini mengindikasikan lepasnya fragmen dengan $\mathrm{m} / \mathrm{z} 111$. Sedangkan puncak dengan $\mathrm{m} / \mathrm{z} 273$ merupakan puncak yang muncul untuk inti xanthon tetraoksi-genasi akibat lepasnya fragmen dengan $\mathrm{m} / \mathrm{z} 137$ yaitu lepasnya molekul geranil $\left(\mathrm{C}_{10} \mathrm{H}_{17}\right)$.

Dengan membandingkan data spektroskopi dan jarak leleh senyawa A dengan literatur, ternyata senyawa A dengan inti xanthon ini merupakan Rubraxanthon ${ }^{[8,9]}$ dengan struktur pada Gambar 5.

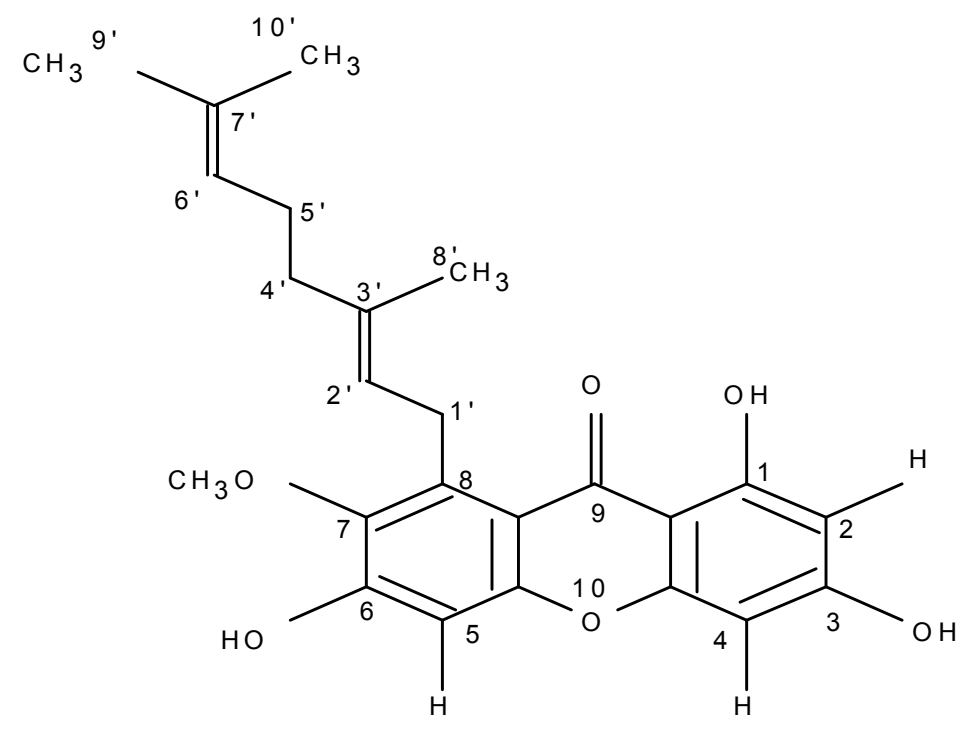

Gambar 5. Struktur Rubaxanthon

Tabel 1. Data Spektroskopi ${ }^{1}$ H RMI, ${ }^{13}$ C RMI dan HSQC Senyawa A dalam d6-Aseton 


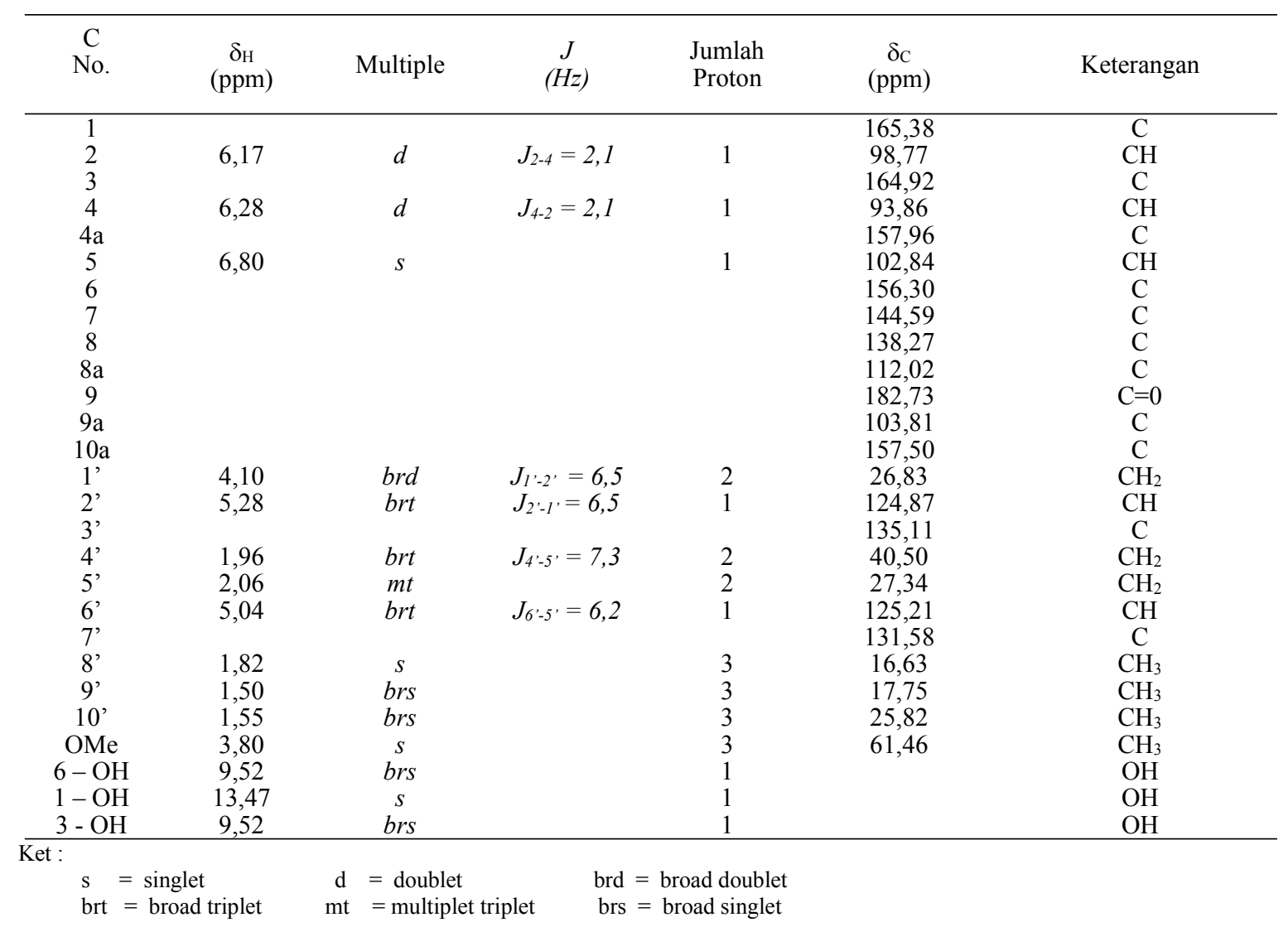

Tabel 2. Data Spektroskpi COSY dan HMBC Senyawa A

\begin{tabular}{|c|c|c|c|c|}
\hline C No. & $\delta_{\text {н }}(\mathrm{ppm})$ & $\begin{array}{c}\delta_{\mathrm{C}} \\
(\mathrm{ppm})\end{array}$ & $\begin{array}{c}\text { COSY } \\
\text { (Interaksi H dengan } \mathrm{H} \text { ) }\end{array}$ & $\begin{array}{c}\text { HMBC } \\
\text { (Interaksi H dengan C ) }\end{array}$ \\
\hline 1 & & 165,38 & & (t) \\
\hline 2 & 6,17 & 98,77 & & $93.86 ; 164,92 ; 103,81$ \\
\hline 3 & & 164,92 & & - \\
\hline 4 & 6,28 & 93,86 & & 165,$38 ; 103,81 ; 98,77 ; 157,96$ \\
\hline $4 a$ & & 157,96 & & - \\
\hline 5 & 6,80 & 102,84 & & 112,$02 ; 144,59 ; 156,30 ; 157,50$ \\
\hline 6 & & 157,50 & & - \\
\hline 7 & & 144,59 & & - \\
\hline 8 & & 138,27 & & - \\
\hline $8 \mathrm{a}$ & & 112,02 & & - \\
\hline 9 & & 182,73 & & - \\
\hline $9 \mathrm{a}$ & & 103,81 & & - \\
\hline $10 \mathrm{a}$ & & 156,30 & & - \\
\hline $1^{\prime}$ & 4,10 & 26,83 & 1,$82 ; 5,28$ & $\begin{array}{l}124,87 ; 112,02 ; 135,11 ; 138,27 ; \\
144,59 ; 16,63 ; 27,34\end{array}$ \\
\hline $2^{\prime}$ & 5,28 & 124,87 & 1,$82 ; 4,10$ & 16,$63 ; 26,83 ; 40,50$ \\
\hline $3^{\prime}$ & & 135,11 & - & - \\
\hline $8^{\prime}$ & 1,82 & 16,63 & 4,$10 ; 5,28$ & 135,$11 ; 40,50 ; 124,87$ \\
\hline 4 & 1,96 & 40,50 & 4,$10 ; 5,28$ & 16,$63 ; 124,87 ; 135,11 ; 27,34$ \\
\hline 5 & 2,06 & 27,34 & 1,$50 ; 1,55 ; 5,03$ & 131,$58 ; 40,50 ; 125,21 ; 135,11$ \\
\hline 6 & 5,04 & 125,21 & 1,$50 ; 1,55 ; 2,06$ & 17,$75 ; 25,82 ; 27,34 ; 40,50$ \\
\hline 7 & & 131,58 & - & \\
\hline $8^{\prime}$ & 1,50 & 17,75 & 2,$06 ; 5,04$ & 125,$21 ; 131,58 ; 25,82 ; 40,50$ \\
\hline $9^{\prime}$ & 1,55 & 25,82 & 2,$06 ; 5,04$ & 125,$21 ; 131,58 ; 17,75 ; 40,50$ \\
\hline $\mathrm{OMe}$ & 3,80 & 61,46 & & 14,59 \\
\hline
\end{tabular}

Tabel 3. Data Perbandingan Senyawa A Dengan Rubraxanthon 


\begin{tabular}{|c|c|c|c|c|}
\hline C No. & $\delta_{\mathrm{C}}$ ppm senyawa $\mathrm{A}$ & $\delta_{\mathrm{C}}$ ppm Rubraxanthon & $\begin{array}{c}\delta_{\mathrm{H}} \mathrm{ppm} \\
\text { senyawa A }\end{array}$ & $\begin{array}{c}\delta_{\mathrm{H}} \mathrm{ppm} \\
\text { Rubraxanthon }\end{array}$ \\
\hline 1 & 165,38 & 165,4 & & \\
\hline 2 & 98,77 & 98,8 & 6,17 & 6,19 \\
\hline 3 & 164,92 & 164,9 & & \\
\hline 4 & 93,861 & 93,8 & 6,28 & 6,29 \\
\hline $4 a$ & 157,96 & 157,5 & & \\
\hline 5 & 102,84 & 102,8 & 6,80 & 6,81 \\
\hline 6 & 156,30 & 156,3 & & \\
\hline 7 & 144,59 & 144,7 & & \\
\hline 8 & 138,27 & 138,3 & & \\
\hline $8 \mathrm{a}$ & 112,02 & 112,0 & & \\
\hline 9 & 182,73 & 182,7 & & \\
\hline $9 \mathrm{a}$ & 103,81 & 103,0 & & \\
\hline $10 \mathrm{a}$ & 157,50 & 156,6 & & \\
\hline $1^{1}$ & 26,83 & 27,3 & 4,10 & 4,12 \\
\hline $2^{1}$ & 124,87 & 124,8 & 5,28 & 5,29 \\
\hline $3^{1}$ & 135,11 & 135,1 & & \\
\hline 8 , & 16,63 & 16,6 & 1,82 & 1,83 \\
\hline $4^{1}$ & 40,50 & 40,2 & 1,96 & 1,97 \\
\hline $5^{1}$ & 27,34 & 26,8 & 2,06 & 2,06 \\
\hline $6^{1}$ & 125,21 & 125,2 & 5,04 & 5,05 \\
\hline $7^{1}$ & 131,58 & 131,5 & & \\
\hline 9 & 17,75 & 17,7 & 1,50 & 1,53 \\
\hline 10 & 25,82 & 25,8 & 1,55 & 1,57 \\
\hline $\mathrm{OMe}$ & 61,46 & 61,4 & 3,80 & 3,80 \\
\hline
\end{tabular}

\section{KESIMPULAN}

Dari fraksi etil asetat diperoleh senyawa murni A $(0,89$ g) berupa kristal jarum berwarna kuning muda, dengan aktifitas KHM masingmasing $125 \mathrm{ppm}$ terhadap Micrococcus luteus ATCC 9342 ppm, 250 ppm terhadap Pseudomonas aeruginosa ATCC 15442, 125 ppm terhadap Staphylococcus aereaus ATCC 6538, 250 ppm terhadap Staphylococcus epidermidis ATCC 12228, dan 250 ppm terhadap Eschericia coli ATCC 8739.

Berdasarkan data spektroskopi disimpulkan bahwa senyawa A adalah rubraxanthon dengan rumus struktur :

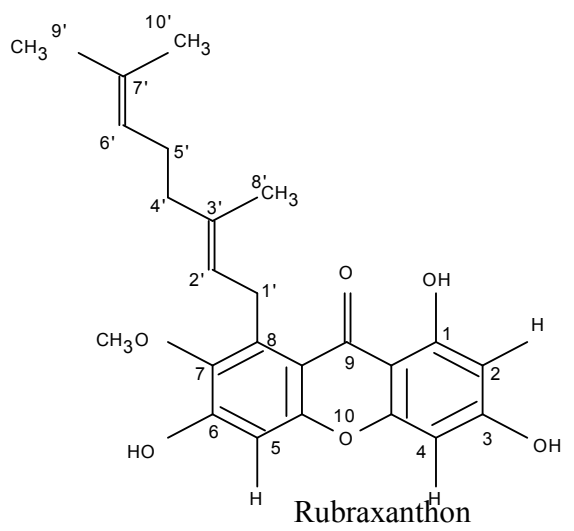

\section{DAFTAR}

1. Burkill, I.H., 1996, A Dictionary of the Economic Products of Malay Peninsula, Volume I, Government of Malaysia and Singapore by the Ministry of Agriculture and Cooperatives, Kuala Lumpur, Malaysia.

2. Leong, Y.W., Harrison, L.J., Bennett, G.J., and Tan., H.T.W., 1996, Forbesione, A Modified Xanthone From Garcinia forbesii.

3. Harrison, L. J., Leong, L. S., Sia, G. L., Sim, K.Y., and Tan, H.T.W., 1993, Xanthones from Garcinia forbesii, Phytochemistry., 33(3): 727-728.

4. Harrison, L.J., and Nilar, 2002, Xanthones from The Heartwood of Garcinia mangostana, Phytochemistry, 60: 541-548.

5. Sutanbawa, M.U. S., 1980, Xanthonoids of Tropical Plants, Tetrahedron, 36: 14651506.

6. Hartati, S., Kardono, L. B. S., Kosela, S., and Sim, K.Y., 2001, Chemical Costituents of Stem Bark of Garcinia tetrandra Piere, Proceeding : International Seminar on Natural Products Chemistry and Utilization of Natural Resources, Kosela, S., dkk (Ed), Universitas Indonesia, Depok.

7. Bennett, G. J., and Lee, H. H., 1989, Xanthones from Guttiferae, Phytochemistry, 28(4): 967-998.

8. Elya, B., Hanafi, M., and Mustika, I., 2000, An Isolation of Chemical Compounds and Antimicrobial Activity of the $\mathrm{N}$-hexane Fraction of Garcinia nervosa Miq. (Bark)", 
Proceeding : The $16^{\text {th }}$ National Seminar on Natural Product, Rahmani, M., dkk. (Ed), The Malaysian Natural Product Society, Malaysia.
9. Ampofo, S. A., and Waterman, P. G., 1986, Xanthones From Three Garcinia Species, J. Pharm. Chem., 25(10): 23512355. 